\title{
Ando meio (des)ligado? Mobilidade e mediação sonora no espaço urbano
}

\section{Simone Pereira de Sá}

\section{Resumo}

0 trabalho aborda práticas de intervenção e escuta sonora a partir de celulares no cotidiano dos espaços urbanos, propondo-se a discutir o papel dos sons e da música como tecnologias do self (De Nora), tanto quanto as acoplagens entre corpo, sujeito e mídias móveis e locativas na construção das paisagens sonoras contemporâneas. Ao mesmo tempo, problematiza 0 argumento de Michael Bull na obra Sound Moves que supõe o uso das mídias móveis para mediação sonora do espaço urbano - em especial Ipods e celulares - como ferramentas que contribuem para 0 declínio da vida pública.

\section{Palavras-chave:}

Mediação sonora. Mobilidade. Música. Som. Mídias locativas.

\section{Simone Pereira de Sá | sibonei.sa@gmail.com}

Doutora em Comunicação pela Universidade Federal do Rio de Janeiro UFRJ. Professor associado do Departamento de Estudos Culturais e Mídia da Universidade Federal Fluminense - UFF.

\section{Introdução}

Ando meio desligado, já nem sinto, meus pés no chão. (Os Mutantes - Meio Desligado)

The world looks friendlier, happier and sunnier when I walk down the street with my Ipod on. It feel like I'm in a movie at times. Like my life has a soundtrack now. (usuário de Ipod, apud BULL, 2007, p. 43)

Na obra Sound Moves - Ipod culture and urban experience, Michaell Bull foca sua análise no que chama de cultura do Ipod, tomando-a como um exemplo central da experiência sonora contemporânea.

De acordo com o autor, o IPod da Apple é 0 primeiro ícone do século XXI, por representar 0 ápice de uma narrativa ocidental de crescente mobilidade e privatização, fruto de um "[...] sublime casamento entre mobilidade, estética e funcionalidade, de som e toque - permitindo aos usuários a posse do mundo auditivo na palma de sua mão" (BULL, 2007, p. 1).

Andando pelas ruas dentro de bolhas sonoras constituídas por suas trilhas musicais, o usuário 
se move antes pelo ritmo de sua própria música do que pelo ritmo da cidade, encerrado dentro de uma zona sonora de imunidade e segurança.

Desta maneira, para 0 autor, o IPod apresenta-se como a melhor metáfora acústica do consumo hiperpós-fordista, pois o consumidor utiliza-se de produtos da indústria cultural para isolar-se e ao mesmo tempo readquirir controle sobre o espaço público.

Em paralelo a esta tendência, Bull também analisa o uso de telefones celulares na mesma direção, uma vez que conectam os usuários à distância, de maneira personalizada, com amigos e família, evitando que eles se defrontem com o caos, poliritmia e desordem sonora da metrópole. ${ }^{1}$

Em resumo, o argumento do autor é o de que ao utilizar Ipods e celulares para a mediação acústica, 0 indivíduo passa a ter 0 controle do espaço auditivo em detrimento de uma abertura para a diversidade cultural da paisagem sonora da cidade que costumava ser a marca registrada do cidadão cosmopolita. Anda pela cidade meio desligado das sonoridades urbanas na exata medida em que se pluga aos fones de ouvido de seu som particular.

0 argumento ecoa uma tradição de pensadores que entendem a mediação tecnológica como mais um elemento a contribuir para a apatia, enclausuramento social e declínio da vida pública, levantando questionamentos que merecem ser discutidos em profundidade.

Três aspectos da análise de Bull, em especial, parecem muito problemáticos: 0 primeiro, de caráter epistemológico, articula-se à sua visão antropocêntrica, que articula 0 uso de Ipods e celulares ao reforço da posição de um sujeito autocentrado, isolado e consumista; o segundo, de caráter metodológico, é o de que 0 autor estende conclusões que obteve a partir da etnografia realizada com informantes caracterizados por ele como heavy users destes artefatos em cidades europeias e americanas para a proposição de um modelo universal - ou pelo menos ocidental - de uso das mídias móveis de mediação sonora. Em terceiro lugar, a experiência de ouvir música através de um artefato não parece ser considerada.

Em perspectiva distinta, Lemos (2007, 2010), um dos autores que no Brasil tem se dedicado pioneiramente a entender a relação entre mídias móveis/locativas e espaços urbanos, chama a atenção para a importância de refletirmos sobre a re-significação do espaço por estes artefatos - em especial o telefone celular. $\mathrm{E}$ defende a ideia de que estamos vivendo uma "virada espacial" nos estudos de comunicação. Assim, se a primeira fase de nossa relação com o ciberespaço foi aquela em que "o lugar não importava" - pois poderíamos nos conectar de qualquer lugar, descorporificados,

No momento em que Bull realizou sua pesquisa - a primeira metade dos anos 2000 - ainda caberia fazer a distinção entre players de MP3 e telefones celulares, uma vez que os recursos dos telefones como reprodutores de música eram limitados. No entanto, desenvolvimentos posteriores permitiram que cada vez mais, na atualidade, os celulares sejam utilizados como players e armazenadores de sons e música. Assim, para os fins da presente discussão, a distinção não será mantida. 
desmaterializados e anônimos; com as mídias locativas ganha força a concepção de que lugar, espaço, território e contexto fazem diferença e tornam-se novamente "sujeitos da ação comunicativa" (LEMOS, 2010, p. 2).

"Virada" que a própria denominação de "mídia locativa" destaca bem, uma vez que se refere a artefatos ou serviços que tenham uma função de localização - tais como smart phones, GPS, redes sem fio, realidade aumentada, etiquetas de radiofrequência etc. - onde 0 "fluxo comunicacional se dá localmente, identificando a posição do usuário" e propondo serviços adequados ao lugar (p. 1); dentre os quais se distinguem os "modos de escuta", que produzem uma leitura sonora do espaço (p. 5).

Na sua reflexão, 0 autor propõe a noção de "território informacional" para circunscrever a reconfiguração dos espaços urbanos a partir das mediações tecnológicas. 0 território informacional é o espaço híbrido, movente, que surge da intersecção entre 0 ciberespaço e 0 espaço urbano a partir da mediação das mídias móveis e locativas. "Por exemplo, o lugar de acesso sem fio em um parque por redes Wi-Fi é um território informacional, distinto do espaço físico parque e do espaço eletrônico internet. Ao acessar a internet por essa rede Wi-Fi, o usuário está em um território informacional imbricado no território físico (e político, cultural, imaginário etc.) do parque, e no espaço das redes telemáticas (LEMOS, 2007, p. 128). Territórios informacionais se configuram por atividades sociais produtoras de pertencimentos simbólicos, afetivos, econômicos; e articulados aos lugares e territórios "físicos" através de relações complexas.

A esta virada espacial, eu gostaria de articular ainda uma "virada material", uma vez que a materialidade dos artefatos de comunicação; e o papel central do corpo como meio de comunicação, mediando os processos comunicativos - em especial, no caso das sonoridades - também tem sido objeto de crescente atenção. Seja a partir do "redescobrimento" da Escola de Toronto, em especial da obra do canadense Marshall McLuhan; seja a partir da Teoria das Materialidades - onde ganha força a ideia de que 0 "observador torna-se inevitavelmente consciente de sua constituição corpórea" como condição complexa de sua própria percepção do mundo (GUMBRECHT, 1998) - ou de outras matrizes teóricas tão distintas quanto a teoria Ator-Rede e discussões da antropologia do consumo, podemos identificar nas mais instigantes reflexões da comunicação um crescente interesse nos aspectos sensoriais e afetivos da comunicação; e do corpo como mediador central dos processos comunicacionais. ${ }^{2}$

Conforme observa De Nora (2000), em reflexão sobre a interação da música com o corpo, esta 
categoria é paradoxal por demarcar os interstícios entre natureza, cultura e tecnologia. E no caso analisado das mídias móveis e/ou locativas, é o agenciamento entre corpos e artefatos que permite não só a ressignificação dos espaços urbanos; mas também das disposições corporais, mentais e psíquicas a partir do uso da música.

Assim, utilizando exemplos que nos permitem perceber a multiplicidade de práticas de intervenção e escuta sonora a partir do uso de celulares no cotidiano da cidade; e ao mesmo tempo dialogando com autores que nos ajudem a construir um arcabouço teórico refinado para lidar com o problema, este artigo propõe-se a uma abordagem inicial do papel das acoplagens entre corpos, sujeitos e mídias móveis e/ou locativas na construção das paisagens sonoras dos espaços urbanos contemporâneos, buscando ao mesmo tempo entender como a música nos afeta.

\section{A música como tecnologia do self}

De Nora, no trabalho Music in everyday life (2000), defende a premissa de que a música deve ser pensada como uma "tecnologia do self". A expressão refere-se ao papel da música acoplandose ao corpo para produzir certos estados energéticos, psíquicos ou mentais modulando humores, ritmo, atenção e também nossa relação espaço-temporal.

Vale observar que seu foco não recai somente sobre usuários de mídias móveis e/ou locativas, mas sim nos usos da música gravada, reproduzida a partir de aparelhos, no cotidiano. Investigando estes usos em detalhes a partir de perguntas sobre quais ocasiões e que tipo de música é utilizada pelos informantes, a autora está interessada em entender não o que a música significa para os seus usuários mas sim como a música atua sobre os corpos e humores, como ela produz efeitos individuais e como afeta as pessoas.

Com esta estratégia, a autora escapa da discussão generalista e hermenêutica sobre as relações entre música e sociedade. E busca estabelecer os links sensoriais, psicossomáticos e emocionais da experiência sonora com a vida cotidiana de maneira detalhista e por isto inovadora e convincente.

Na sua argumentação, ela propõe que a música é um veículo, um importante agenciador para regulação, ordenação e configuração de situações e papéis sociais:

"0 vocabulário de usar a música para ativar 0 que vc "precisa" é um discurso comum do self, parte da tecnologia literária através da qual a subjetividade é constituída como um objeto de autoconhecimento." Mas, os discursos específicos que os respondentes invocam como descritores de "o que eles precisam" não são flutuantes: são normalmente ligados a exigências práticas de suas apropriações e interações com os outros, tal como a discussão a seguir, sobre "trabalho emocional" deixa claro. Por exemplo, Ângela, 18 anos, estudante do ensino médio em 
Nova York, diz: "Se eu precisar realmente me acalmar e relaxar eu vou colocar uma música mais lenta" (DE NORA, 2000, p. 50, tradução nossa). ${ }^{3}$

Também enfatizando 0 aspecto de relaxamento, a autora cita Monica, uma estudante inglesa de 21 anos que descreve a sua música predileta para a hora do banho: "Tomando banho, sim, eu ouço Enya. É realmente agradável e me traz paz." (DE NORA, 2000, p. 50, tradução nossa). ${ }^{4}$

Como passar do estado de cansaço após um dia de trabalho para outro de animação para uma festa? Como lidar com o sentimento de raiva após uma briga familiar? Como relaxar após uma semana de adrenalina intensa? Como concentrar-se para uma leitura? Como dar 0 tom de um encontro íntimo? Como andar de bicicleta num ritmo adequado? Em todas estas situações, os informantes apontam o uso da "música certa" como crucial. Estratégia identificada pela autora como de reflexividade estética do sujeito (GIDDENS, 1990; LASH; URRY, 1994), que lança mão de bens culturais de maneira autoconsciente, pragmaticamente, para regular os estados do self e adequá-los à situações, papéis sociais e contextos altamente heterogêneos, incongruentes e discrepantes tais como os da atualidade (DE NORA, 2000, p. 51).

Esta mesma forma de utilizar a música para a regulação de estados psíquicos também é declarada pelos informantes de Bull (2007, p. 29, tradução nossa), em diversos momentos de sua etnografia.

Samantha, por exemplo, declara que:

Eu mantenho um pouco de música lenta que me dá uma sensação de paz e tranquilidade quando estou em ambientes movimentados ou caóticos, como no metrô. Nora Jones é um grande exemplo. Aí, eu também gosto muito de música 'pra cima', pra dançar. Isso é bom não só pra malhar, mas também quando eu estou simplesmente andando pela cidade - me coloca num humor otimista. Tal como Britney Spears (que eu normalmente não escuto), que tem algumas novas canções dance boas, como 'Toxic'. ${ }^{5}$

Joey vai também nesta direção, quando detalha seu uso do Ipod:

No momento em que chego na plataforma do metrô, estou ouvindo meu 'mix da manhã.' Este mix são músicas dos anos 80 , que vão desde Eurythmics a Blondie e The Smiths. É uma mistura sutil e 'pra cima' que me acorda e me deixa motivado para o meu dia. Eu sempre

The vocabulary of using music to achieve what you 'need' is a common discourse of the self, part of the literary technology trough which subjectivity is constituted as an object of self-knowledge. But, the specific discourses that respondents invoke as descriptors of "what they need" are not free floating: they are typically linked to practical exigencies of their appropriation and to interactions with others, as the discussion below of 'emotional work" makes clear. For example, Angela, an eighteen-year-old high school student in New York City says,' If I need to really settle down and just like relax or something I'll put on slow music.'

Having a bath, yeah, I listen to Enya; it's really nice and peaceful.

I keep some slow music that gives me a calm, peaceful feeling when I'm in busy or chaotic settings, like on the subway. Nora Jones is a great example. Then, I also like really upbeat, dance-style music. This is good not only for the gym, but also when I'm just walking around the city - puts me in an upbeat mood. Like Britney Spears (who I normally don't listen to) has some good new dance songs, like 'Toxic'. 
planejo o que vou ouvir e la mistural reflete 0 que eu quero ouvir ou sentir naquele momento. ${ }^{6}$

A mesma informante complementa que a única forma de concentrar-se para ler em espaços públicos da cidade de Nova York é tendo fones no ouvido com algum tipo de fundo musical que a faça concentrar-se: "Eu acho que é porque a música é familiar e eu não me distraio por ela. É ruído de fundo, que é previsível, seguro e sob meu controle."

Um terceiro informante, Jason, acredita que pode modificar até os humores alheios a partir da sua trilha particular: "Às vezes eu acho que posso acalmar as pessoas simplesmente olhando para elas enquanto escuto música. E algumas vezes, quando elas olham para mim, acho que elas mudam, porque reconhecem que estou num 'bom lugar"” (BULL, 2007, p. 42, tradução nossa). ${ }^{8}$

Sami, por sua vez, enfatiza a relação afetiva da trilha sonora com a cidade:

Refiro-me ao meu Ipod como o meu marca-passo, ela me ajuda a encontrar os lugares.
Eu quase que exclusivamente viajo para NYC INova Yorkl quando não estou em Londres. Eu tenho uma lista de reprodução musical dedicada làs viagensl, chamada de 'estado de espírito de NY'. Isso inclui uma grande quantidade de rap de Nova York e jazz nova-iorquino da costa leste (BULL, 2007, p. 37, tradução nossa). ${ }^{9}$

\section{E Jason enfatiza a reconfiguração do espaço e}

dos transeuntes:

Meu mundo fica melhor. Eu me emociono com as coisas, incluindo as pessoas que vejo e os meus pensamentos em geral. [...] Por exemplo, eu me lembro claramente de ouvir 'Stuck in a Moment', do U2, e eu estava olhando para algumas das pessoas ao meu redor num café, com olhar de ansiedade em seus rostos e angústia geral. Isso me fez querer abraçá-los e dizer-Ihes que 'está tudo bem' [...] (BULL, 2007, p. 41, tradução nossa). ${ }^{10}$

As citações são relevantes por enfatizarem a especificidade das mídias móveis em três aspectos fundamentais: primeiramente, elas potencializam as estratégias de autorreflexividade e produção do self no percurso cotidiano de seus usuários pela cidade. Ao permitirem que 0 usuário carregue sua enciclopédia musical na palma da mão - seja a

By the time I get to the subway platform I am listening to my morning mix. This mix is '80s music ranging from Eurythmics to Blondie and the Smiths. It's an upbeat and a subtle mix that wakes me up and gets me motivated for my day. I always plan what I will listen to and it reflects what I want to hear or feel at that time.

I think it's because the music is familiar and I don't get distracted by it. It is background noise, that is predictable, secure and in my control.

Sometimes, I think I can calm people down just by looking at them when I'm listening to music. And sometimes, when they look at me, I think they do 'shift', because they recognize that I'm in a 'good place'.

I refer to my Ipod as my pacemaker, it helps me find that place. I almost exclusively travel to NYC when not in London. I have a dedicated playlist called 'NY state of mind'. This includes a lot of New York rap music and NY east coast jazz.

My world looks better. I get more emotional about things, including the people I see and my thoughts in general. [...] For example, I can distinctly remember listening to U2 'Stuck in a moment' and I was looking at some of the people standing around me in a coffee shop, with the look of anxiety on their faces and general angst. It made me want to hug them and tell them 'it's ok' [...]. 
partir do armazenamento prévio de música, seja a partir do acesso a sites e rádios on-line - 0 usuário regula seus humores, afetos e sensibilidades de maneira bastante detalhista e sofisticada.

Em segundo lugar, porque 0 aspecto sensorial, de experiência corpórea permitida pela mobilidade do player é fundamental e definidor da experiência: andar por uma rua do centro de Nova York ouvindo uma certa trilha produz uma experiência específica, distinta da escuta daquela mesma trilha no espaço doméstico, por exemplo. Neste caso, é a articulação entre o corpo se movendo num certo espaço urbano ao som de uma certa trilha que faz a diferença.

Finalmente, e como consequência das premissas anteriores, cabe ainda enfatizar a ressignificação afetiva do espaço urbano e dos transeuntes, que ganham novos sentidos para 0 usuário a partir daquela trilha sonora particular.

Rediscutindo a definição de mídia locativa de Lemos anteriormente mencionada, cabe propor que, no caso de nossos exemplos, o fluxo comunicacional também se dá localmente, uma vez que o local importa e é sujeito da ação comunicativa.

Entretanto, o vetor de localização, que nos exemplos do autor ocorrem na direção mídia-usuário (0 celular que localiza a posição do usuário no espaço e oferece um serviço), aqui ocorre também na direção inversa, uma vez que a função locativa ocorre a partir da acoplagem do corpo com o celularenquanto-player-musical, ressignificando o espaço; ao mesmo tempo que o espaço "orienta" as escolhas.

\section{Cosmpolitismo mediado}

Na sua análise, Bull parece se aproximar da discussão de De Nora sobre a autorreflexividade do sujeito, ao entender a "filtragem" musical realizada por seus informantes como uma estetização do cotidiano. Entretanto, no argumento do autor, esta estetização é entendida como "transcendência" da realidade multi-rítmica das ruas para um mundo fantasioso e utópico povoado pelas trilhas sonoras mono-rítmicas que produzem simplificação e empobrecimento da experiência urbana (BULL, 2007). Experiência que 0 autor denomina criticamente de "cosmopolitismo mediado", adquirido através do consumo; e que se opõe à sua valorização da interação social face a face das ruas presente no cosmopolitismo "tradicional".

Neste sentido, a análise de De Nora torna-se mais produtiva, por apontar 0 caráter paradoxal destas estratégias de autorregulação, que tanto - e talvez ao mesmo tempo - podem servir ao empoderamento e autoemancipação do indivíduo em relação ao contexto social; quanto também, ao contrário, podem ser incorporadas pelo capitalismo avançado em sua demanda por ordem, padronização e por um sujeito consumidor. Entretanto, fiel aos princípios da etnografia, a resposta às premissas não se dá a priori, mas sim a partir de referências específicas a atores reais.

Além disto, a autora descarta qualquer relação mecânica, essencialista ou determinista da música com os corpos e com o self. Assim, ainda 
que a música seja um ingrediente importante na organização dos afetos, energias, atenção e engajamento social, ela não deve ser pensada como estímulo, agindo sobre os indivíduos como um agente externo (DE NORA, 2000, p. 61).

Ao contrário, os "efeitos" da música sobre os corpos e 0 self supõem a atenção a todo um contexto extra-musical que orienta as escolhas o que explica porque a mesma música tocada em contextos distintos não produzirá o mesmo efeito; e onde as acoplagens com os corpos têm um lugar central. Tal como a informante de Bull que diz que ouve Britney Spears no metrô, mesmo não tendo o hábito de ouvi-la "normalmente", em outros ambientes.

Citando o pioneiro estudo de Willis (1978 apud DE NORA, 2000) sobre os bikeboys e o tipo de música que eles escolhiam para andar de bicicleta; e posteriormente aprofundando a análise no capítulo sobre a seleção e eficácia de músicas para uma aula de aeróbica, a autora demonstra que, para cada situação, não há músicas definidas "a priori", mas sim aquelas que, testadas em sua atuação sobre os corpos, funcionaram bem para produzir o efeito esperado - sensação de velocidade no caso dos bikeboys; de marcação rítmica no caso da aula aeróbica; e de reorganização espaço-temporal, nos dois casos.

Neste sentido, a sugestão da música como transporte, nos levando a outras situações emocionais, a outros momentos temporais, tornase literal, uma vez que ela transporta os corpos destes informantes do estado de inércia para o estado de movimento; e vice-versa, quando é chegada a hora de "diminuir"; garantindo-lhes um ritmo, uma pulsação ou um conjunto de valores literalmente "encorporados", conforme enfatizado por um dos informantes de Willis e comprovado por qualquer transeunte que já utilizou um fone de ouvido em seu percurso pela cidade: "Você pode ouvir o beat dentro da sua cabeça, não é?... Você é levado pela batida." (WILLIS, 1978 apud DE NORA, 2000, p. 7, tradução nossa). ${ }^{11}$

\section{Acoplagens}

A noção de acoplagem merece destaque por evocar um conjunto de ressonâncias teóricas relevantes para iluminar aspectos das questões aqui encaminhadas.

Primeiramente, ela evoca a discussão de Gumbrecht (1998) e de Gumbrecht e Pfeiffer (1994), no contexto da Teoria das Materialidade. Conforme apontado por Felinto (2001), Felinto e Andrade (2005) e Sá (2004), esta faz um movimento de desvio da reflexão sobre a mediação tecnológica do campo hermenêutico, político e/ou ideológico em favor da materialidade ou da concretude de cada um dos canais de comunicação.

Nesta direção, uma de suas importantes sugestões é a de que os meios de comunicação são elementos constitutivos das estruturas, da 
articulação e da circulação de sentido, deixando marcas que se imprimem nas relações que as pessoas mantêm com seus corpos, com sua consciência e com suas ações.

Na esteira destas reflexões, Gumbrecht enfatiza a importância de compreendermos as formas de acoplagem estrutural entre diferentes sistemas, ou seja, a forma como um novo sistema emerge da relação do meu corpo com o computador, por exemplo, formando novas cadeias de significantes onde a noção de ritmo é fundamental. ${ }^{12}$

Em segundo lugar, ela nos remete à teoria AtorRede, em especial à discussão de Latour (1986, 1991) sobre a acoplagem estrutural entre atores humanos e inumanos que atuam dentro de uma complexa rede sociotécnica produzindo híbridos, sugerindo-nos uma sociologia da técnica menos preocupada com a distinção de atores humanos e inumanos nas redes tecnológicas e mais interessada em discutir a distribuição ou delegação de tarefas dentro do processo, conforme discuto em Sá (2009).

Na sua perspectiva, qualquer artefato técnico tem características antropomórficas uma vez que é um delegado que desempenha atividades ou tarefas designadas por humanos. Mais do que isto, um artefato técnico é primeiramente desenhado por humanos, passando num segundo momento a substituir a ação de humanos, para finalmente prescrever a ação de humanos de certa maneira.

Esta delegação, entretanto, também se dá em via de mão dupla, uma vez que o sistema - como qualquer outra tecnologia - pode ser visto como a automatização ou cristalização de um processo social, cultural e material que sedimenta relações sociais.

Uma terceira ressonância da ideia de acoplagem nos remete a outra tradição, de autores como Miller (1994) e Mizrahi (2006), ligados aos estudos da antropologia do consumo. Nada tendo a ver com as correntes teóricas anteriores, também torna-se produtiva para a reflexão, uma vez que enfatiza a importância não só de compreendermos a dimensão simbólica dos bens materiais mas também a natureza física dos objetos ou a relação "entre pessoa e coisa".

Conforme observa Mizrahi (2006), o que está em jogo na sua proposta é entender não só o caráter simbólico dos bens materiais, mas 0 da acuidade de certos objetos para traduzir certas particularidades do mundo simbólico; ao mesmo tempo que a sutileza dos processos de diferenciação possibilitados por certos artefatos materiais.

0 consumo é pensado, nesta perspectiva, como um "processo de objetificação" (MILLER, 1994 apud MIZRAHI, 2006) e os artefatos materiais são mediadores fundamentais e concretos dos processos de afirmação identitária e construção de valores. ${ }^{13}$ 
0 que as perspectivas têm em comum é a ênfase na necessidade de ultrapassarmos as distinções sujeito-objeto e as relações de causalidade antropocêntricas, que colocam o sujeito humano como o centro das intencionalidades. Deslocar esta centralidade e perceber o fenômeno comunicativo como rede constituída por atores, onde cada um dos agentes produz diferença e altera 0 conjunto, me parece 0 aspecto mais importante do argumento para nossa análise, que nos afasta da premissa de Bull sobre o sujeito autocentrado, isolado e desligado do espaço.

Pelo contrário, elas nos permitem ir além das dicotomias sujeito-objeto e cultura-técnica, nos desafiando a pensar na articulação corpomídiaslocativas-música-espaçourbano como que criando um agenciamento específico, híbrido, de onde saem todos os elementos modificados. Neste caso, tal como na discussão de Mizrahi (2006, p. 12) sobre a roupa e o corpo do funk.

Materialidade e agência funcionam simultaneamente e no registro de um não-dualismo entre pessoas e coisas. Um precisa do outro para causar 0 efeito que provocam ao passar. Pessoa e coisa estão, assim, fundidas. E é o resultado dessa interação que é capaz de 'chamar a atenção'.

É esta acuidade que faz do player/celular que toca música um objeto central da cultura musical contemporânea: como vimos, elementos tais como tamanho, mobilidade, fones de ouvido, convergência com outras mídias permitindo 0 acesso a rádios e sites e capacidade de armazenamento musical; além da forma específica como ele se acopla ao corpo que se move pelo espaço das cidades são alguns dos elementos que devemos levar em conta ao analisarmos a especificidade desta experiência sonora.

\section{Passado /memória}

Ao discutir as diferentes formas como a música reorganiza nossa percepção espaço-temporal, De Nora se detém nas questões do passado e da memória, uma vez elas são mencionadas por suas informantes de maneira insistente.

Tal como Lucy, que declara na entrevista que 0 verão de 67 foi marcado pelo hit $A$ whiter shade of pale. E que recentemente, aos 52 anos, ouviu esta música numa loja de shopping, olhou para uma outra mulher que parecia ter a mesma idade e que ambas concordaram que aquela música funcionava como a porta de entrada para um túnel do tempo rumo ao passado.

Outros exemplos são a da filha que ouvia a sonata preferida do pai morto para se lembrar dele; e da esposa que teve um caso extraconjugal cuja "canção-tema", eleita em conjunto pelos dois amantes, sempre que ouvida anos 
depois do caso extinto ainda a transportava ao passado.

Estes usos cotidianos demonstram como a música, e mais amplamente o mundo dos sons, funciona como um "contêiner da memória" acionando instantaneamente uma rede de associações que recupera humores, emoções e sentimentos. E assim trazendo de volta, seja a especificidade de uma situação, de um evento ou de uma relação, seja a generalidade de uma época (anos 60, por exemplo). ${ }^{14}$

Entretanto, cabe mais uma vez ressaltar 0 cuidado da autora em não sugerir nenhuma relação mecânica ou determinista da música com o passado. Aqui, a ideia é a de que a música ajuda-nos a "reconhecer quem éramos num certo momento" (DE NORA, 2000, p. 65), rememorarmos 0 "agenciamento estético que existia naquele momento anterior", recontando e dando sentido a nossa trajetória. Neste sentido, as mídias móveis e locativas novamente reforçam a noção de tecnologia do self - uma vez que são artefatos para a produção de uma narrativa unificada e coerente, ainda que sempre dinâmica, sobre nossas autobiografias. ${ }^{15}$
Esta reconstrução pode ser individual, como vimos nos casos anteriores, mas também coletiva. ${ }^{16}$ Para além dos exemplos do universo estritamente musical, Lemos (2010) descreve alguns projetos de anotações sonoras do espaço urbano, tais como Murmur - hear you are; Península Voices e Defina sua Cidade que fazem uso de mídias locativas para contar/ouvir histórias associadas aos lugares por onde os usuários circulam, caso dos dois primeiros exemplos; ou para ouvir textos de Gregório de Matos espalhados por pontos turísticos da cidade de Salvador, na Bahia, no terceiro exemplo."0 lugar é aqui não apenas o percurso, mas um 'disparador' de histórias. 0 que emana dos lugares é 0 conteúdo criado por moradores em entrevistas sobre o local" (LEMOS, 2010, p. 12) - no caso do Murmur e do Península Voices; ou de "[...] instaurar um estranhamento local e problematizar a visão idílica instituída pelos poderes públicos, principalmente pelo turismo" no caso do Defina sua cidade. ${ }^{17}$

Desta maneira, as narrativas podem reatualizar ou problematizar o passado, recontar histórias, criar identidades coletivas, contribuindo para os laços de sociabilidade e para a re-territorialização.

A discussão da oralidade como tecnologia do pensamento foi colocada de maneira pioneira pela Escola de Toronto - a partir da obra de McLuhan, Innis, Ong - dentre outros.

15 Sobre a perspectiva da memória em permanente construção, ver a discussão de Pereira (2002, p. 60), em especial o conceito de transmnese.

16 Ainda que, para Halbwachs, a memória seja sempre coletiva e social, acompanho Pereira (2002) que propõe pensar na memória individual como um polo de funcionamento que compõe a memória social.

17 No momento, desenvolvo o projeto Cartografia Sonora do Rio de Janeiro - apoiado pelo CNPq, que explora também a relação entre lugares, memória, identidade, mídias locativas e plataformas musicais e que em breve será disponibilizado na internet. 


\section{0 bonde do funk mobile}

Antes das considerações finais, utilizarei ainda um último exemplo de intervenção no espaço urbano a partir da apropriação coletiva das mídias móveis, que testemunhei num transporte público da cidade do Rio de Janeiro.

Há cerca de um ano eu esperava pelo ônibus numa parada da Zona Sul do Rio de Janeiro. Ao meu lado, três rapazes aparentando ter entre 13 e 16 anos, que mencionaram morarem na favela da Rocinha, situada não longe dali.

Pegamos o mesmo ônibus. E tão logo passamos a roleta do veículo relativamente vazio, eles escolheram os bancos do fundo e começaram a tocar funk carioca no volume máximo, a partir do celular de um deles. Discutindo suas preferências musicais e fazendo um tipo de acompanhamento percussivo com as mãos e pés, eles passaram 0 tempo da viagem demonstrando ostensivamente que se divertiam muito com a performance improvisada que invadiu o espaço acústico do transporte.

Eles poderiam ter optado por ouvir a trilha direto dos fones de ouvido. Entretanto, escolhendo "abrir o som" para todo o ônibus, eles forçaram os outros passageiros a compartilharem seu gosto musical e interviram na paisagem sonora ambiente, uma vez que era impossível ignorá-los devido ao volume não só do som mas de toda a performance.

Observei que algumas pessoas no ônibus usavam player de música conectados no fone de ouvido; uma ou outra lia. Mas, gostando ou não, ninguém reclamou e a viagem transcorreu tranquilamente rumo ao ponto final, sem discussão entre os passageiros, mistura de trabalhadores de camadas populares e estudantes que embarcaram na parada em frente à Universidade PUC-Rio.

Para entender o significado deste episódio, precisamos nos remeter ao contexto do funk na cidade do Rio de Janeiro - trilha sonora dos bailes de periferia e favelas cariocas, que mobiliza milhares de jovens das camadas populares. Assim, ainda que sua origem seja o Miami Bass americano, as letras fazem a crônica do cotidiano e problemas da favela, incluindo pobreza, violência, tráfico de drogas e embate entre polícia e bandidos comuns nestas áreas, tendo um fortíssimo apelo ao território e à comunidade.

Apesar disto, a consolidação do funk como expressão dos subúrbios e favelas cariocas não implicou no seu reconhecimento cultural ampliado (como aconteceu décadas antes com 0 samba, por exemplo). Desde os anos 80, quando o gênero se consolidou no Rio, sua história é de perseguição e estigmatização pela mídia, pela polícia e pelos formadores de opinião, que repetidamente lançam mão de argumentos de pânico moral para analisarem o fenômeno (FREIRE FILHO; HERSCHMAN, 2003).

Desta forma, os usos que os rapazes fazem do celular me interessam, primeiramente, por tratar-se de um uso desviante, uma apropriação que transforma a escuta isolada e individual de música numa outra forma coletiva e 
compartilhada, produzindo uma narrativa sonora sobre "quem são".

Ao produzirem tal transformação, acredito que as táticas (CERTEAU, 1990) dos garotos também podem ser lidas no sentido de afirmação identitária e em reterritorialização do espaço público a partir da criação de um território informacional de pertencimento no interior do veículo. Pois, se uma certa classe média carioca não tem interesse de ir à favela muito facilmente, eles forçam as pessoas a ouvirem um pouco da narrativa sobre seu cotidiano.

Apropriação tecnológica, contexto, disputa dos sentidos do espaço acústico e o papel da música móvel como elemento importante de reterritorialização, construção de narrativas, laços de sociabilidade e identidades coletivas são novamente as palavras-chave para meu argumento.

0 mesmo cenário também apresenta práticas de escuta diversas desta primeira modalidade, pois também observei o uso de players individuais por usuários que tocavam sua própria trilha sonora, de maneira privada, personalizada e imersiva, à maneira dos informantes de Bull.

Entretanto, de novo, a moldura da experiência urbana do Rio de Janeiro me parece crucial para 0 enquadramento destas práticas, pois, tratando-se de uma metrópole com problemas de assalto e violência, estar atento nas ruas é uma atitude obrigatória. Assim, o isolamento numa bolha acústica ao cruzar a cidade tanto quanto a exibição de laptops, câmeras fotográficas e smartphones nas ruas, tal como podemos ver em outras cidades do mundo, é menos usual, uma vez que estar em estado de alerta e não desviar a atenção de bolsas e artefatos é uma atitude "encorporada" pelos habitantes da cidade.

Outra característica que também merece atenção é - paradoxalmente - a efervescente sociabilidade da cidade. Clichês á parte, o fato é que falar com estranhos na rua e nos transportes é bastante comum, o direito á privacidade - tão óbvio na Londres onde Bull fez parte de seu trabalho - não é garantido e conseguir ficar calado numa fila é um desafio, quando não uma falta de educação.

Neste contexto, milhares de pessoas usam seus players para ouvir música; mas, é comum a cena de retirarem um dos fones do ouvido e conversarem enquanto o outro fica plugado, 0 que problematiza novamente a noção de bolha acústica e de atitude imersiva, alheia ao entorno. Ao contrário, o modelo que parece melhor traduzir a experiência das ruas cariocas é o das múltiplas camadas de interação sobrepostas - ouvir música mais conversar, mais estar atento aos gritos da barraca do camelô na calçada, do flanelinha que interpela 0 transeunte etc. etc.

\section{Considerações finais}

A partir das discussões, entendemos o papel das mídias móveis e/ou locativas como central para a reconfiguração das paisagens sonoras contemporâneas a partir da criação de territórios 
informacionais. Entretanto, contrariamente ao argumento de Bull, não necessariamente estes artefatos isolam os indivíduos em bolhas acústicas impermeáveis e alheias às sonoridades da cidade.

0 esforço deste artigo foi, portanto, 0 de relativizar o modelo proposto por Bull, sugerindo usos e apropriações das mídias móveis e/ou locativas em múltiplas direções e a partir de diversas acoplagens, seja nas práticas individuais do uso do celular como player de música; seja nas práticas coletivas exemplificadas pela apropriação do celular para ouvir funk ou para produzir anotações sonoras compartilhadas.

A análise destas acoplagens - investigando em especial o ritmo/movimento híbrido do corpomídia em cada situação e da rede que se forma a partir deste movimento - merece posterior aprofundamento. Entretanto, creio que estes usos me ajudaram ainda a demonstrar 0 argumento de que os espaços urbanos são historicamente construídos; e que a cidade é um tecido produzido pela pluralidade de usos e múltiplas experiências, onde diálogo, conflito e negociação são parte da batalha por significação de seus habitantes, escrevendo suas histórias e inscrevendo-se no tecido urbano através de suas práticas ordinárias (CERTEAU, 1990).

Desta maneira, não podemos tomar como um dado a premissa - predominantemente resultante de certa experiência europeia que foi generalizada para o "resto do mundo" - do declínio do espaço público e a consequente hipertrofia da vida privada.
Assim, ainda que a globalização produza cidades similares e não-lugares tais como aeroportos e shoppings, ela convive com a pluralidade e diversidade de modo que a cultura e a tecnologia são articuladas; e com os modos particulares como as mídias locativas são apropriadas por diferentes usuários, produzindo agenciamentos também específicos, onde o lugar importa, e muito.

Conforme observa Lemos (2007, p. 135):

$$
\begin{aligned}
& \text { Definitivamente à medida que vamos des- } \\
& \text { plugando nossas máquinas de fios e cabos, } \\
& \text { à medida que redes de telefonia celular, } \\
& \text { bluetooth, RFID ou Wi-Fi fazem das nossas } \\
& \text { cidades máquinas comunicantes desplugadas } \\
& \text { e sem fio, paradoxalmente, vamos criando } \\
& \text { projetos que buscam exatamente o contrário, } \\
& \text { territorialização, ancoragem no espaço físico, } \\
& \text { acoplagem a coisas, lugares, objetos [...]. }
\end{aligned}
$$

No caso da música e do ruidoso mundo das sonoridades mediado por smartphones, esta é uma premissa instigante, cuja análise em detalhes é o desafio que se descortina a partir da presente discussão.

\section{Referências}

BULL, M. Sound Moves. Ipod culture and urban experience. Routledge, London, New York, 2007.

CERTEAU, M. de. L 'invention du quotidien - 1a. arts de faire. Paris: Gallimard, 1990.

DE NORA, T. Music in everyday life. Cambridge, U.K.: Cambridge Univ. Press, 2000.

FELINTO, E. Materialidades da comunicação: 
por um novo lugar da matéria na teoria da comunicação. Revista Eletrônica Ciberlegenda, n. $5,2001$.

FELINTO, E.; ANDRADE, V. - A vida dos objetos: um diálogo com o pensamento da materialidade da comunicação. Revista Contemporânea, Salvador. v. 3, n. 1, p. 75-94. Jan./jun. 2005.

FREIRE FILHO, J.; HERSCHMANN, M. Funk carioca: entre a condenação e a aclamação na mídia. Revista EC0-Pós, Rio de Janeiro, v. 6, n. 2, ago./dez 2003.

GIDDENS, A. The consequences of modernity. Cambridge: Polity, 1991.

GUMBRECHT, H. U. Corpo e forma: ensaios para uma crítica não-hermenêutica. Organizado por João Cezar de Castro Rocha. Rio de Janeiro: EDUERJ, 1998.

\section{GUMBRECHT, H. U.; PFEIFFER, L. Materialities}

of communication. Stanford: Stanford University Press, 1994.

\section{KITTLER, F. Gramophone, Film, Typewriter.}

Stanford: Stanford University Press, 1999.

HALBWACHS, M. A memória coletiva. São Paulo: Vértice, Ed. Revista dos Tribunais, 1990.

\section{LASH, S.; URRY, J. Economies of Signs and}

Space. London: Sage, 1994.

LATOUR, B. "Where are the missing masses? A sociology of a few mundane artefacts". In:
BIJKER, W. E.; LAW, J. (Org.). Shaping

Technology/Building Society: studies in Sociotechnical Change, Cambridge, MA: MIT Press, 1991. p. 225-258.

LATOUR, B.; Woolgar, S. Laboratory Life: the construction of Scientific Facts. Princenton: Princenton University Press, 1986.

LEMOS, A. Você está aqui! Mídia locativa e teorias "Materialidade da Comunicação" e "Ator-Rede". In: ENCONTRO DA COMPÓS, 19., 2010, Rio de Janeiro. Anais... Rio de Janeiro: Compós, 2010. . Cidade e mobilidade: telefones celulares, funções pós-massivas e territórios informacionais. São Paulo, Revista Matrizes, n.1, p. 121-137, out. 2007.

MILLER, D. Artefacts and the meaning of things. In: INGOLD, T. (Org.). Companion Encyclopedia of Anthropology. London: Routledge, 1994.

MIZRAHI, M. Funk e mimesis: trocas entre 0 gosto local e o gosto local. In: ENCONTRO ANUAL DA ANPOCS, 30. 2006, Caxambu. Anais... Caxambu: ANPOCS, 2006.

PEREIRA, V. A. Comunicação e memória: estendendo McLuhan. 2002. Tese (Doutorado em Comunicação) - Escola de Comunicação, Universidade Federal do Rio de Janeiro. Rio de Janeiro, 2002.

SÁ, S. P. de Explorações da noção de materialidade da Comunicação. Revista Contracampo, Niterói, v.10/11, p. 31-44, 2004. 
Se você gosta de Madonna também

vai gostar de Britney. Ou não!? Gêneros,

gostos e disputas simbólicas nos sistemas de

recomendação musical". E-Compós, Brasília, v.

12, n. 2, maio/ago. 2009. 


\section{Mobility and sound mediation in} urban space

\section{Movilidad y mediación sonora en el espacio urbano}

\section{Abstract:}

The paper focuses on practices of listening to music from mobile phones in everyday urban spaces, proposing to discuss the role of sound and music as technologies of the self (De Nora), as well as couplings between the body, subject and mobile/ locative media in the construction of contemporary soundscapes. At the same time, criticizes Michael Bull's work Sound Moves, assuming the use of mobile media for mediation sound of urban space - especially iPods and cellphones - as tools that contribute to the decline of public life.

\section{Keywords:}

Sound mediation. Mobility. Music. Sound. Locative media.

\section{Resumen:}

El estudio aborda las prácticas de intervención y escucha sonora através de los teléfonos móviles en los espacios urbanos cotidianos, proponiendo discutir el papel de los sonidos y la música como tecnologías del yo (De Nora), así como los acoplamientos entre el cuerpo, el sujeto y los medios de comunicación móviles y locativas en la construcción de los paisajes sonoros contemporáneos. Al mismo tiempo, cuestiona el argumento de la obra Sound Moves, de Michael Bull, asumiendo el uso de medios móviles de sonido de la mediación del espacio urbano - en especial iPods y teléfonos móviles - como herramientas que contribuyen a la disminución de la vida pública.

\section{Palabras clave:}

Mediaciones sonoras. Movilidad. Musica. Sonido. Medios locativos. 


\section{Expediente}

A revista E-Compós é a publicação científica em formato eletrônico da Associação Nacional dos Programas de Pós-Graduação em Comunicação (Compós). Lançada em 2004, tem como principal finalidade difundir a produção acadêmica de pesquisadores da área de Comunicação, inseridos em instituições do Brasil e do exterior.
E-COMPÓS I www.e-compos.org.br I E-ISSN 1808-2599

Revista da Associação Nacional dos Programas de Pós-Graduação em Comunicação.

Brasília, v.14, n.2, maio/ago. 2011.

A identificação das edições, a partir de 2008 passa a ser volume anual com três números.

\section{CONSELHO EDITORIAL}

Afonso Albuquerque, Universidade Federal Fluminense, Brasil Alberto Carlos Augusto Klein, Universidade Estadual de Londrina, Brasil Alex Fernando Teixeira Primo, Universidade Federal do Rio Grande do Sul, Brasil Ana Carolina Damboriarena Escosteguy, Pontifícia Universidade Católica do Rio Grande do Sul, Brasil

Ana Gruszynski, Universidade Federal do Rio Grande do Sul, Brasil Ana Silvia Lopes Davi Médola, Universidade Estadual Paulista, Brasi André Luiz Martins Lemos, Universidade Federal da Bahia, Brasil Ângela Freire Prysthon, Universidade Federal de Pernambuco, Brasil Angela Cristina Salgueiro Marques, Faculdade Cásper Líbero (São Paulo), Brasil Antônio Fausto Neto, Universidade do Vale do Rio dos Sinos, Brasil Antonio Carlos Hohlfeldt, Pontifícia Universidade Católica do Rio Grande do Sul, Brasil Antonio Roberto Chiachiri Filho, Faculdade Cásper Libero, Brasil Arlindo Ribeiro Machado, Universidade de São Paulo, Brasil Arthur Autran Franco de Sá Neto, Universidade Federal de São Carlos, Brasil Benjamim Picado, Universidade Federal Fluminense, Brasil César Geraldo Guimarães, Universidade Federal de Minas Gerais, Brasil Cristiane Freitas Guttreind, Pontifícia Universidade Católica do Rio Grande do Sul, Brasi Denilson Lopes, Universidade Federal do Rio de Janeiro, Brasil Denize Correa Araujo, Universidade Tuiuti do Paraná, Brasil Edilson Cazeloto, Universidade Paulista , Brasil Eduardo Peñuela Cañizal, Universidade Paulista, Brasi Eduardo Vicente, Universidade de São Paulo, Brasi Eneus Trindade, Universidade de São Paulo, Brasil Erick Felinto de Oliveira, Universidade do Estado do Rio de Janeiro, Brasil Florence Dravet, Universidade Católica de Brasília, Brasil Francisco Eduardo Menezes Martins, Universidade Tuiuti do Paraná, Brasi Gelson Santana, Universidade Anhembi/Morumbi, Brasil Gilson Vieira Monteiro, Universidade Federal do Amazonas, Brasi Gislene da Silva, Universidade Federal de Santa Catarina, Brasil Guillermo Orozco Gómez, Universidad de Guadalajara Gustavo Daudt Fischer, Universidade do Vale do Rio dos Sinos, Brasil Hector Ospina, Universidad de Manizales, Colômbia Herom Vargas, Universidade Municipal de São Caetano do Sul, Brasil leda Tucherman, Universidade Federal do Rio de Janeiro, Brasil Inês Vitorino, Universidade Federal do Ceará, Brasi Janice Caiafa, Universidade Federal do Rio de Janeiro, Brasil Jay David Bolter, Georgia Institute of Technology Jeder Silveira Janotti Junior, Universidade Federal de Pernambuco, Brasil João Freire Filho, Universidade Federal do Rio de Janeiro, Brasi
John DH Downing, University of Texas at Austin, Estados Unidos José Afonso da Silva Junior, Universidade Federal de Pernambuco, Brasil José Carlos Rodrigues, Pontifícia Universidade Católica do Rio de Janeiro, Brasil José Luiz Aidar Prado, Pontifícia Universidade Católica de São Paulo, Brasil José Luiz Warren Jardim Gomes Braga, Universidade do Vale do Rio dos Sinos, Brasil Juremir Machado da Silva, Pontifícia Universidade Católica do Rio Grande do Sul, Brasil Laan Mendes Barros, Universidade Metodista de São Paulo, Brasil Lance Strate, Fordham University, USA, Estados Unidos Lorraine Leu, University of Bristol, Grã-Bretanha Lucia Leão, Pontifícia Universidade Católica de São Paulo, Brasil Luciana Panke, Universidade Federal do Paraná, Brasil Luiz Claudio Martino, Universidade de Brasilia, Brasil Malena Segura Contrera, Universidade Paulista, Brasil Márcio de Vasconcellos Serelle, Pontifícia Universidade Católica de Minas Gerais, Brasil Maria Aparecida Baccega, Universidade de São Paulo e Escola Superior de Propaganda e Marketing, Brasil

Maria das Graças Pinto Coelho, Universidade Federal do Rio Grande do Norte, Brasil Maria Immacolata Vassallo de Lopes, Universidade de São Paulo, Brasil Maria Luiza Martins de Mendonça, Universidade Federal de Goiás, Brasil Mauro de Souza Ventura, Universidade Estadual Paulista, Brasil Mauro Pereira Porto, Tulane University, Estados Unidos Nilda Aparecida Jacks, Universidade Federal do Rio Grande do Sul, Brasi Paulo Roberto Gibaldi Vaz, Universidade Federal do Rio de Janeiro, Brasi Potiguara Mendes Silveira Jr, Universidade Federal de Juiz de Fora, Brasil Renato Cordeiro Gomes, Pontifícia Universidade Católica do Rio de Janeiro, Brasil Robert K Logan, University of Toronto, Canadá

Ronaldo George Helal, Universidade do Estado do Rio de Janeiro, Brasil Rosana de Lima Soares, Universidade de São Paulo, Brasil Rose Melo Rocha, Escola Superior de Propaganda e Marketing, Brasil Rossana Reguillo, Instituto de Estudos Superiores do Ocidente, Mexico Rousiley Celi Moreira Maia, Universidade Federal de Minas Gerais, Brasil Sebastião Carlos de Morais Squirra, Universidade Metodista de São Paulo, Brasi Sebastião Guilherme Albano da Costa, Universidade Federal do Rio Grande do Norte, Brasil

Simone Maria Andrade Pereira de Sá, Universidade Federal Fluminense, Brasil Tiago Quiroga Fausto Neto, Universidade de Brasília, Brasi Suzete Venturelli, Universidade de Brasília, Brasil Valério Cruz Brittos, Universidade do Vale do Rio dos Sinos, Brasil Valerio Fuenzalida Fernández, Puc-Chile, Chile Veneza Mayora Ronsini, Universidade Federal de Santa Maria, Brasil Vera Regina Veiga França, Universidade Federal de Minas Gerais, Brasil

\section{COMISSÃO EDITORIAL}

Adriana Braga I Pontifícia Universidade Católica do Rio de Janeiro, Brasil Felipe Costa Trotta I Universidade Federal de Pernambuco, Brasil

CONSULTORES AD HOC

Bárbara Heller, Universidade Paulista, Brasil

Luciana Mielniczuk, Universidade Federal do Rio Grande do Sul, Brasil Micael Herschmann, Universidade Federal do Rio de Janeiro, Brasil EDIČ̃̃ DE TEXTO E RESUMOS I Susane Barros SECRETÁRIA EXECUTIVA I Juliana Depiné EDITORAÇ̃o ELETRÔNICA I Roka Estúdio TRADUÇÃO I Sabrina Gledhill, Sieni Campos, Robert Finnegan
COMPós I www.compos.org.br

Associação Nacional dos Programas de Pós-Graduação em Comunicação

Presidente

Julio Pinto

Pontifícia Universidade Católica de Minas Gerais, Brasi

juliopinto@pucminas.br

Vice-presidente

Itania Maria Mota Gomes

Universidade Federal da Bahia, Brasi

itania@ufba.br

Secretária-Gera

Inês Vitorino

Universidade Federal do Ceará, Brasil

inesvict@gmail.com 